\title{
Differential expression of the ccn3 (nov) proto- oncogene in human prostate cell lines and tissues
}

\author{
M Maillard, B Cadot`, R Y Ball, K Sethia, D R Edwards, B Perbal, R Tatoud
}

\begin{abstract}
Aims-To investigate the expression of the human cen3 (hecn3; nov) proto-oncogene, a member of the CCN family of proteins, in prostate epithelial cells and prostate tissue samples.

Methods-Normal adult prostate luminal epithelial cells immortalised by SV40 large T (PNT1A and PNT1B), metastatic tumours (LNCaP, DU-145, and PC-3), and prostate tissue samples from patients with benign prostatic hyperplasia (BPH) and prostatic adenocarcinoma were used. hecn 3 (nov) mRNA was measured by the reverse transcription polymerase chain reaction (RT-PCR) and hCCN3 (NOV) protein expression was determined by immunochemistry.
\end{abstract}

Results-hccn3 (nov) RNA values were higher in PC-3 cells than in the other prostate cell lines. The immortalised normal cell lines either did not express hecn3 (nov) RNA (PNT1B) or expressed very low amounts (PNT1A). BPH samples expressed variable amounts of hecn 3 (nov) RNA. With the use of immunocytochemistry, all cell lines except PNT1A and PNT1B were shown to contain hCCN3 (NOV) protein. hCCN3 (NOV) was localised mainly in the epithelial compartment of BPH and adenocarcinoma samples, and there was evidence of luminal secretion.

School of Biological Sciences, University of East Anglia, Norwich NR4 7TJ, UK

M Maillard

D R Edwards

$\mathrm{R}$ Tatoud

UFR de Biochimie, Université Paris 7 - D. Diderot, 2 Place Jussieu, 75005 Paris, France

B Cadot

B Perbal

Norfolk and Norwich Health Care NHS

Trust, Norwich,

NR1 3SR, UK

R Y Ball

K Sethia

${ }^{\star} \mathrm{MM}$ and $\mathrm{BC}$ contributed equally to this work.

Correspondence to: Dr Tatoud, Biomedical Research Centre, University of Dundee, Ninewells Hospital (level 5), Dundee DD1 9SY, UK

roger@tatoud.fsnet.co.uk

Accepted for publication 1 May 2001
Alterations of the short arm of chromosome 8 may be important for the initiation or progression of prostate cancer. For instance, overexpression of the c-myc gene, localised on chromosome 8q, has been documented in prostate cancer when compared with benign prostate hyperplasia $(\mathrm{BPH})$ or normal tissue..$^{5-8}$ Amplification, rearrangement, and increased expression of c-myc were also detected in the human prostate carcinoma cell lines LNCaP and PC-3, and the SV40 large $\mathrm{T}$ antigen immortalised cell line PNT1A. ${ }^{9}{ }^{10}$ Interestingly, the human ccn3 (hccn3; nov) gene is localised on chromosome 8q24.1, proximal to c-myc. ${ }^{11}$ Therefore, genetic alterations of this gene may contribute to prostate tumorigenesis.

The ccn3 (nov) proto-oncogene (nephroblastoma overexpressed gene) has been characterised from avian nephroblastoma, where it was expressed in all samples tested and in the kidney at the embryonic stage, ${ }^{12}$ but only in small amounts in adult normal kidneys. ${ }^{13}$ The hCCN3 (NOV) protein is structurally related to a family of early response proteins that probably play a role in cell growth regulation. It is a member of the growing family of secreted regulatory proteins termed CCN. ${ }^{15}{ }^{16}$ This family of proteins initially comprised CCN3 (NOV), CCN2 (CTGF; connective tissue growth factor), ${ }^{17}$ and CCN1 (CYR61), ${ }^{18}$ but now includes several other members such as CCN4 (ELM1/WISP1), CCN5, and CCN6. ${ }^{19}$ The comparative analysis of their primary structure has established that they are mosaic proteins that contain 38 conserved cysteine residues and four structural motifs, namely: (1) an insulin-like growth factor (IGF) binding protein (IGFBP) module, (2) a von Willebrand type C module probably involved in oligomerisation, (3) a thrombospondin (type 1 repeat) module thought to be involved in the interaction with extracellular matrix molecules, and (4) a C-terminal motif proposed to represent a dimerisation domain. Despite the presence of an IGFBP domain, the hCCN3 (NOV) protein should be considered as distinct from the human IGFBP family. ${ }^{20}$ The primary function of the CCN proteins is not to bind IGF but to interact with extracellular matrix or cell membranes, or to regulate in both positive and negative ways the action of other growth factors, such as fibroblast growth factor 2 and transforming growth factor $\beta$ (TGF- $\beta$ ), the actions of which are enhanced by CCN1 (CYR61). ${ }^{21-23}$ CCN2 (CTGF) is also a downstream target of the TGF- $\beta$ signalling pathway. ${ }^{24}$

The hocn3 (nov) gene encodes a putative $32 \mathrm{kDa}$ secreted protein $(44-48 \mathrm{kDa}$ in cell culture), which can be glycosylated. ${ }^{14}$ The hCCN3 (NOV) protein is detected in vivo as an extracellular matrix associated protein. ${ }^{25} \mathrm{An}$ $\mathrm{N}$-terminal truncated isoform of hCCN3 (NOV) has been detected in the conditioned medium of cells expressing hCCN3 (NOV), 
either endogenously or ectopically, ${ }^{26}$ and in the nucleus of human cancer cells. ${ }^{27}$ The expression of the hccn 3 (nov) gene has been investigated in several tumours. In Wilms's tumour it was raised in various histological types of tumours, with an inverse correlation with WT-1 gene expression. $^{28} \mathrm{Ex}$ vivo assays confirmed that hccn3 (nov) was a potential target of WT-1, which downregulated its expression. ${ }^{29}$ Early experiments established that the overexpression of ccn3 (nov) in normal chicken embryonic fibroblasts has an inhibitory effect on cell growth in vitro, whereas expression of an $\mathrm{N}$-terminal truncated form of CCN3 (NOV) results in the induction of morphological transformation. ${ }^{12}$ Moreover, the expression of $\operatorname{ccn} 3$ (nov) was associated with cell quiescence and was downregulated on induction of cell proliferation after serum or tetradecanoyl phorbol acetate induction and oncogenic transformation of chicken embryo fibroblasts. ${ }^{30}$ The hCCN3 (NOV) protein could be a negative regulator of cell growth that can antagonise the stimulatory effects of CCN2 (CTGF) and CCN1 (CYR61). Therefore, genetic or functional alterations of the hccn 3 (nov) gene and protein could be involved in prostate tumorigenesis.

To determine whether hccn3 (nov) is involved in prostatic tumorigenesis we examined its expression in prostate cell lines derived from normal and tumorigenic tissues, in $\mathrm{BPH}$ and in primary and metastatic prostatic adenocarcinoma. Our results show that hecn 3 (nov) RNA and protein are differentially expressed in normal and cancer cell lines and that the hCCN3 (NOV) protein is localised mainly in the epithelial compartment of prostate tissue samples. Accordingly, the differential expression of the hccn3 (nov) gene may be an important event in prostate tumorigenesis.

\section{Materials and methods}

CELL LINES AND HUMAN TISSUES

PNT1A and PNT1B are normal adult epithelial prostate cells immortalised by SV40 T antigen. ${ }^{31}$ These cell lines have retained epithelial and differentiation markers such as cytokeratin 18-19, prostatic acid phosphatase, prostate specific antigen, and androgen receptors. ${ }^{31}$ PC-3, DU145 , and $\mathrm{LNCaP}$ are epithelial prostate cancer cell lines derived from metastases to lymph node, brain, and bone, respectively, and were purchased from the ATCC, Rockville, Maryland, USA. All cell lines were grown in RPMI 1640 supplemented with $10 \%$ heat inactivated fetal calf serum, $2 \mathrm{mM} \mathrm{L}$-glutamine and $10 \mathrm{mM}$ Hepes (Life Technology, Paisley, UK) at $37^{\circ} \mathrm{C}$ in a $5 \% \mathrm{CO}_{2}$ enriched atmosphere.

Human tissue was obtained by transurethral resection from six men with benign nodular hyperplasia of the prostate (median age, 75 years; range, 67-83), by transurethral resection or radical prostatectomy from 20 cases of primary adenocarcinoma of the prostate (median age, 75 years; range, 54-91), and from four cases of metastatic carcinoma, three within lymph nodes and one pleural (median age, 76 years; range, 68-85). Tissue for histopathological assessment and immunohistochemical staining was fixed in $10 \%$ unbuffered formal saline. In addition, samples of the tissue from men with $\mathrm{BPH}$ were frozen in liquid nitrogen immediately after removal for total RNA extraction.

\section{REVERSE TRANSCRIPTION AND POLYMERASE}

CHAIN REACTION (RT-PCR)

Total RNA was extracted from cell cultures or $\mathrm{BPH}$ samples with RNAzol B reagent (Biogenesis, Poole, Dorset, UK) according to the manufacturer's instructions. For reverse transcription, first strand synthesis was carried out using random hexamer primer (Amersham Pharmacia Biotech, Amersham, Buckinghamshire, UK) and murine moloney virus reverse transcriptase (Superscript-RT; Life Technology). A $10 \mu \mathrm{g}$ aliquot of RNA were used for reverse transcription and then $1 \mu \mathrm{g}$ of reverse transcribed RNA was used in each PCR amplification. Glyceraldehyde 3-phosphate dehydrogenase (GAPDH) amplification was used as an internal control for amplification. PCR was also performed on a sample that was reverse transcribed in the absence of reverse transcriptase to assess DNA contamination. Optimum conditions were determined previously to ensure that the RT-PCR did not reach the plateau before the end of the reaction, permitting a semiquantitative measurement.

The oligonucleotide primers and PCR conditions were: hocn3 (nov): 5'-TCAGCGCTGC CCTCCCCA-3' (sense), and 5'-CGGACCC CAGCAACCAGACT-3' (antisense); 30 cycles of one minute at $94^{\circ} \mathrm{C}$, one minute at $67^{\circ} \mathrm{C}$, and one minute at $72^{\circ} \mathrm{C}$. GAPDH: 5'-AGACAG CCGCATCTTCTTGTGC-3' (sense), and 5'CTCCTGGAAGATGGTGATGG-3' (antisense); 18 cycles of one minute at $94^{\circ} \mathrm{C}$, one minute at $60^{\circ} \mathrm{C}$, and one minute at $72^{\circ} \mathrm{C}$. The PCR amplification was followed by a 10 minute final extension at $72^{\circ} \mathrm{C}$. All experiments were carried out in triplicate in a DNA thermocycler. PCR amplification products were electrophoresed on a $1.8 \%$ agarose gel stained with ethidium bromide. Digested pGEM-3 DNA was used as a size marker (Promega, Southampton, UK).

\section{IMMUNOCHEMISTRY}

For immunocytochemistry, prostate cell lines were grown in chamber slides (Lab-Tek; Nunc, Merck, Leicester, UK) to $70 \%$ confluence. Cells were washed in phosphate buffered saline (PBS) and permeabilised in methanol/acetone (2/1) for 10 minutes at $4^{\circ} \mathrm{C}$, and then washed twice with PBS.

Human tissue was fixed in $10 \%$ unbuffered formal saline and embedded in paraffin wax. Sections were cut at $4-5 \mu \mathrm{m}$. Paraffin wax sections were dewaxed in xylene and rehydrated through a graded series of alcohol into distilled water. Endogenous peroxidase activity was quenched by incubation in $3 \% \mathrm{H}_{2} \mathrm{O}_{2}$ for 30 minutes, followed by a water rinse. Microwave assisted antigen retrieval was performed in $0.01 \mathrm{M}$ sodium citrate $(\mathrm{pH} 6)$, for three cycles of five minutes (medium/low setting), followed by 

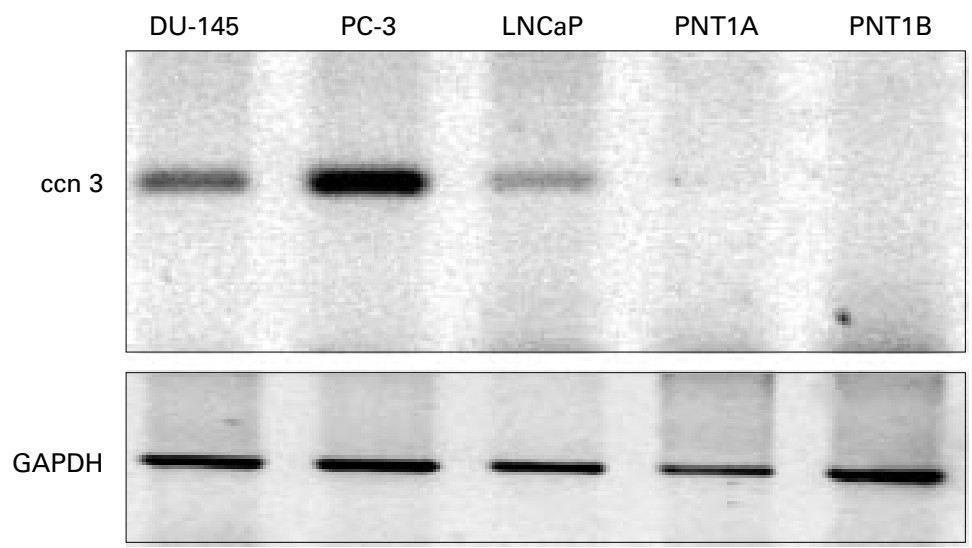

Figure 1 Detection of human ccn3 (nov) $m R N A$ in human prostatic cell lines by reverse transcription polymerase chain reaction (RT-PCR). A $1 \mu \mathrm{g}$ aliquot of reverse transcribed RNA was subjected to PCR with specific primers for ccn3 (nov) and glyceraldehyde 3-phosphate dehydrogenase (GAPDH). PCR products were run on a 1.8\% agarose gel and stained with ethidium bromide. Colours have been inverted for better clarity. Results shown represent a typical experiment.
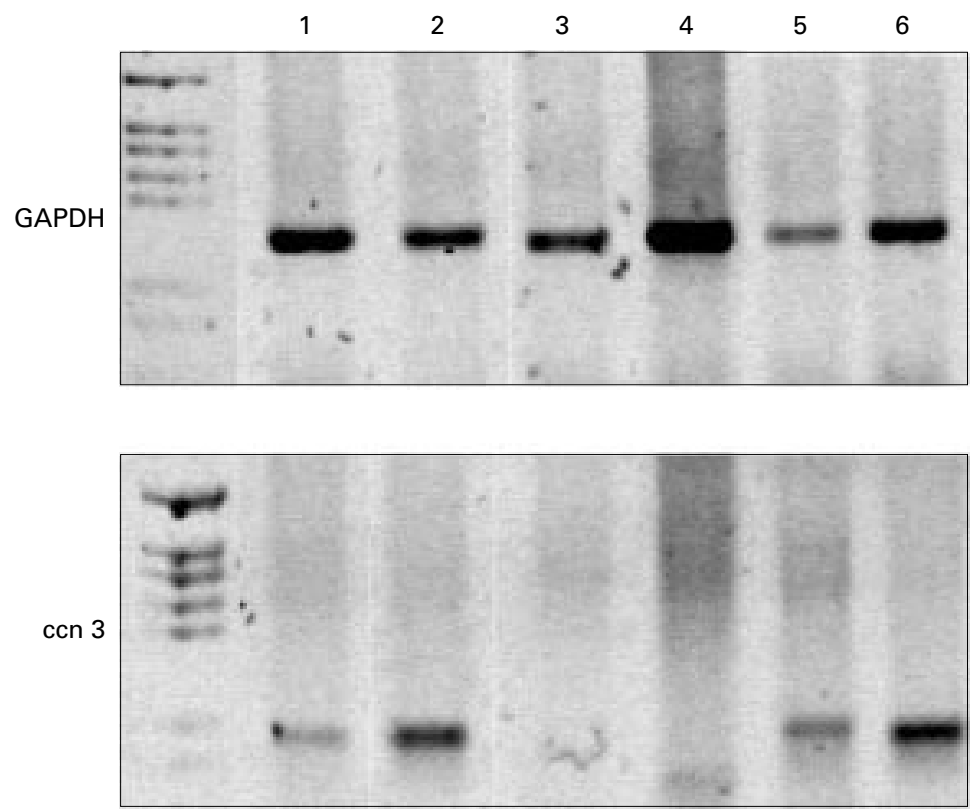

Figure 2 Detection of human ccn3 (nov) RNA by reverse transcription polymerase chain reaction (RT-PCR) in benign prostate hyperplastic tissues. $A 1 \mu \mathrm{g}$ aliquot of reverse transcribed RNA was subjected to PCR with specific primers for ccn 3 (nov) and glyceraldehyde 3-phosphate dehydrogenase (GAPDH). PCR products were run on a $1.8 \%$ agarose gel and stained with ethidium bromide. The numbers refer to the patient numbers. First lane, PGEM-3Z size marker (Promega). Colours have been inverted for clarity.

cooling to $50^{\circ} \mathrm{C}$ and a final round of microwaving for five minutes, cooling, and a final rinse in water.

For both cell culture and human tissue, nonspecific binding sites were blocked by incubation in $3 \%$ bovine serum albumin (BSA) in PBS for two hours at room temperature in a humidified atmosphere. Subsequently, cell preparations and sections were incubated overnight with the specific anti-hCCN3 (NOV) antibody (K19M) at a $1 / 500$ dilution in $3 \% \mathrm{BSA}$ in PBS at $4^{\circ} \mathrm{C}$. This was followed by three washes of five minutes in PBS, incubation in horseradish peroxidase conjugated goat antirabbit secondary antibody at a dilution of 1/200 (Dako, Ely, UK) in 3\% BSA in PBS for one hour. After three washes in PBS, the peroxidase enzyme reaction was developed with an AEC staining kit (Sigma Aldrich, Poole, Dorset, UK). Cells and tissues samples were counterstained in haematoxylin for 15 seconds. Sections were mounted with Glycergel (Dako) under glass coverslips. Controls consisted of incubation leaving out the primary antibody or using a rabbit immunoglobulin fraction prepared from sera of non-immunised rabbits (Dako). The hCCN3 (NOV) stained sections showed no non-specific staining and the two controls (no primary antibody and non-specific primary antibody) were both negative.

\section{Results}

EXPRESSION OF hCCN3 (NOV) RNA BY PROSTATE CELL LINES AND BPH SAMPLES

By means of RT-PCR using primers specific for exon 2 of the hccn3 (nov) transcript, we showed that hocn 3 (nov) RNA is expressed in all prostate cancer cell lines. One immortalised prostate cell line, PNT1A, showed a very faint amplification product for hccn3 (nov) (fig 1). PNT1B did not express the hccn3 (nov) transcript. The PC-3 cancer cell lines expressed the highest amounts of the transcript. For $\mathrm{BPH}$ samples, RT-PCR was performed at least twice for each sample and results were compared with both GAPDH values and total RNA by gel electrophoresis. Figure 2 shows representative PCR results. Four of the six patients expressed the hccn3 (nov) transcript. The absence of DNA contamination was confirmed by PCR carried out on a sample where the reverse transcription step was performed in the absence of reverse transcriptase (not shown).

EXPRESSION OF hCCN3 (NOV) PROTEIN BY PROSTATE CELL LINES

Immunocytochemical studies demonstrated hCCN3 (NOV) protein in all cancer cell lines (fig $3 \mathrm{~A}-\mathrm{C}$ ). hCCN3 (NOV) was localised in the cytoplasm of the cell, mainly in perinuclear granules. The intensity of staining varied between cells in an individual culture. Most cells showed moderate to strong immunoreactivity, but some showed weak or no staining. There was no obvious difference in the quality or intensity of staining for hCCN3 (NOV) between positive prostate cell lines. Normal SV40 immortalised cell lines PNT1A and PNT1B did not stain positive (fig 3D), consistent with their lack of expression of RNA (PNT1B) or very low expression (PNT1A).

DETECTION OF hCCN3 (NOV) PROTEIN IN BPH SAMPLES

Immunohistochemical staining for hCCN3 (NOV) showed moderate to strong staining of acinar epithelial cells (fig 3E,F); it was cytoplasmic and had a reticulated, granular, or lumpy quality. In some cells, it was most pronounced in the periapical cytoplasm. In some glands, the luminal contents (fig 3E) and luminal macrophages were weakly to moderately positive for hCCN3 (NOV). Luminal secretion staining for hCCN3 (NOV) was probably the result of apical secretion by acinar epithelial cells (fig 3F). Basal cells were difficult to interpret but some (perhaps a minority) did seem to be positive for hCCN3 (NOV) (fig 3F). Vascular endothelial cells, nerves, and stromal smooth muscle cells were focally immunoreactive for $\mathrm{hCCN} 3$ 
(NOV). Endothelial cell and nerve cell staining was moderate to strong, and that of smooth muscle cells was weak to moderate. Stromal macrophages showed lumpy moderate to strong cytoplasmic staining, particularly in foci of granulomatous prostatitis in one patient

DETECTION OF hCCN3 (NOV) PROTEIN IN PRIMARY PROSTATIC ADENOCARCINOMA

Nineteen of the 20 cases of primary prostatic adenocarcinoma showed some immunohistochemical staining for hccn3 (nov) (fig 3G,H).

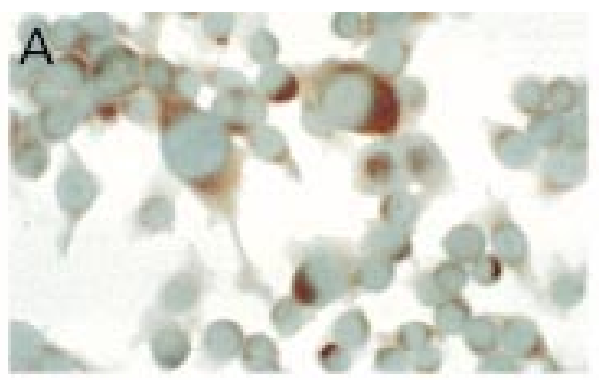

Figure 3

Immunocytochemical localisation of the human CCN3 (NOV) protein in prostate cell lines $(A-D)$, benign nodular hyperplasia of the prostate $(E, F)$, and adenocarcinoma of the prostate $(G, H)$. The cell lines are: $(A) P C-3,(B)$ $D U-145$, (C) LNCaP, and (D) PNT1B; original magnification, $\times 200$. (E) Dilated glands in benign prostatic hyperplasia (BPH) showing immunostaining of lining epithelium and luminal contents; original magnification, $\times 200$. (F) Strong apical staining of epithelial cells and focal, weaker staining of basal cells (arrows) in $\mathrm{BPH}$; original magnification, $\times 300$. (G) Gleason pattern 3 adenocarcinoma of the prostate showing

cytoplasmic

immunostaining for $h C C N 3$ (NOV); original magnification, $\times 200$. $(H)$ Ring-like staining of lumina in prostatic adenocarcinoma; original magnification, $\times 300$.
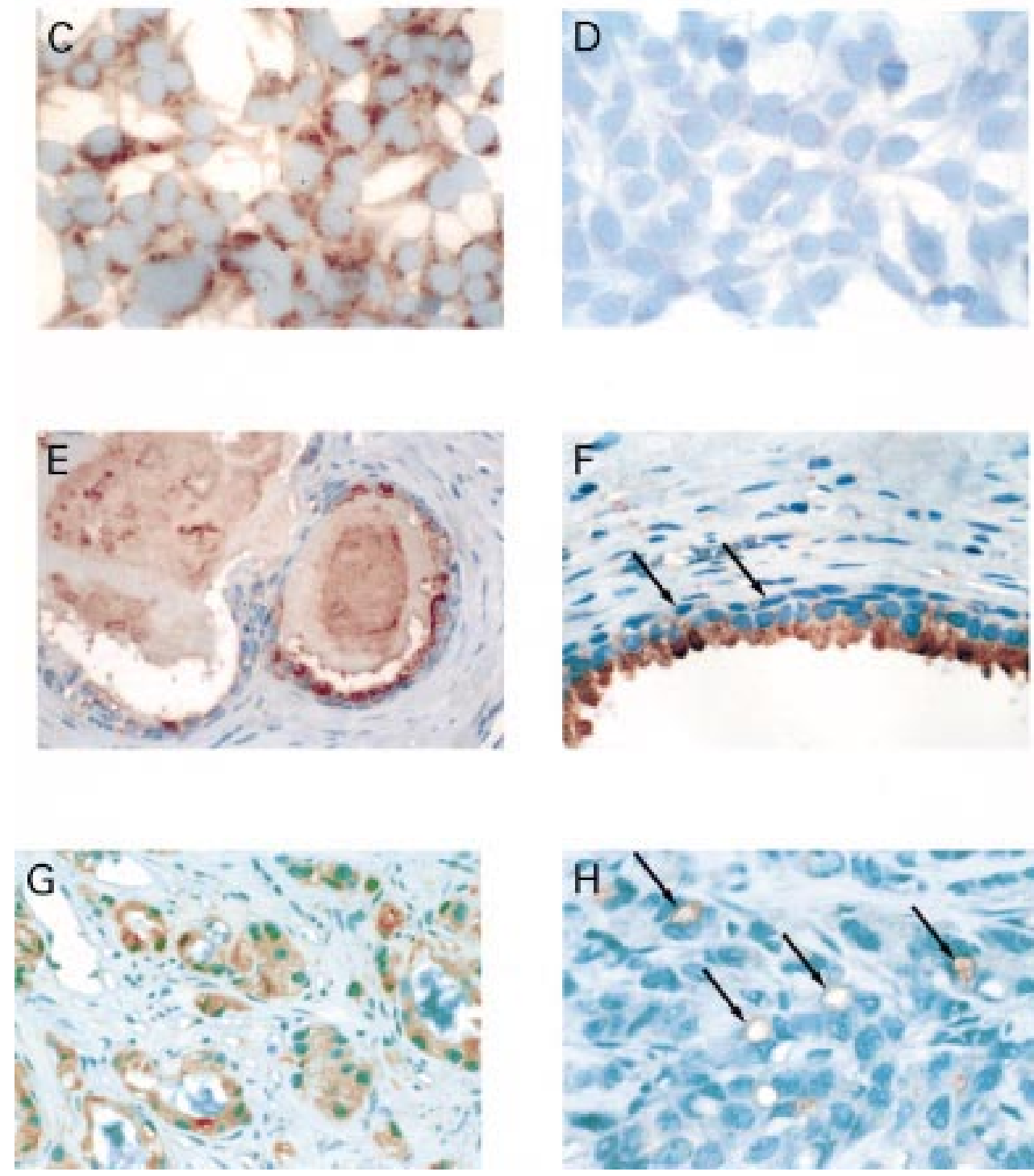

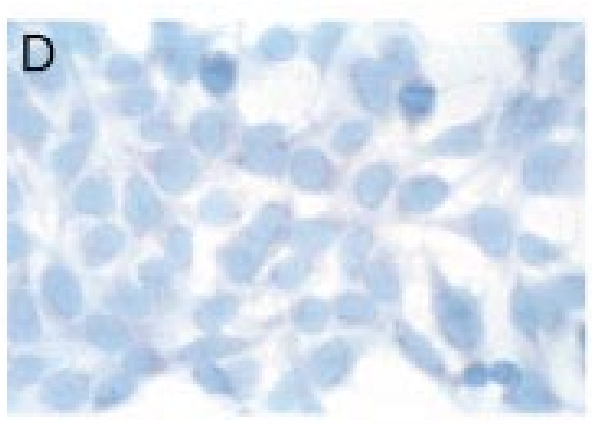

Staining was patchy and variable in intensity. Tumour cells showed granular, cytoplasmic immunoreactivity, similar to that seen in normal and hyperplastic acinar cells. Some glands showed diffuse staining of their contents or dense, ring-like staining related to glandular lumina (fig $3 \mathrm{H}$ ).

The 20 cases contained 31 Gleason patterns (table 1). There was no obvious relation between quality or intensity of staining for hCCN3 (NOV) and Gleason pattern.

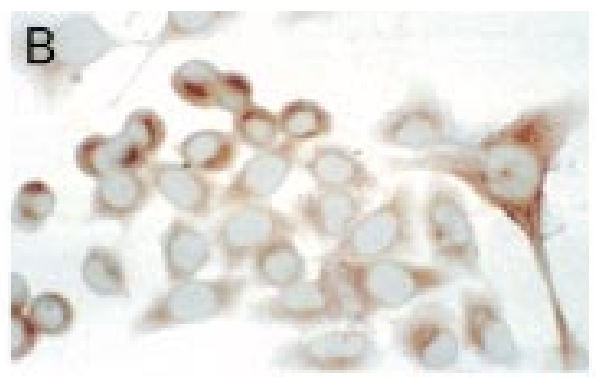


Table 1 Immunohistochemical detection of human CCN3 (hCCN3; NOV) protein in human primary adenocarcinoma of the prostate

\begin{tabular}{lll}
\hline Gleason pattern & Stained for hCCN3 & $\begin{array}{l}\text { Not stained for } \\
\text { hCCN3 }\end{array}$ \\
\hline 1 & 0 & 1 \\
2 & 3 & 0 \\
3 & 12 & 0 \\
4 & 7 & 1 \\
5 & 6 & 1 \\
Total & $28(90 \%)$ & $3(10 \%)$ \\
\hline
\end{tabular}

Paraffin wax sections were immunostained with either the hCCN3 (NOV) specific antibody (K19M) or a rabbit immunoglobulin fraction prepared from sera of non-immunised rabbits.

DETECTION OF hCCN3 (NOV) PROTEIN IN METASTATIC PROSTATIC ADENOCACINOMA The three lymph node metastases showed focal cellular and glandular luminal staining, similar to that seen in primary tumours. Residual lymphoid cells in the lymph nodes did not stain for hCCN3 (NOV). The pleural metastasis showed no staining, but this sample was the only one obtained at necropsy, and there could be a technical reason for this negative result.

\section{Discussion}

hCCN3 (NOV) is a founding member or the CCN family of proteins. It can bind IGF, but with a very low affinity, ${ }^{32}$ and it seems that its role in vivo is associated with other functions, yet to be determined. We found that hecn 3 (nov) RNA and protein were expressed in human prostate tissue and cell lines. Our PCR experiments showed that hocn3 (nov) mRNA expression is mainly restricted to prostate cancer cell lines. The two normal immortalised prostate epithelial cells used in our study either showed very low mRNA expression or no expression at all. These results were confirmed by immunocytochemistry (fig 3A-D). For the cancer cell lines, overexpression of hccn 3 (nov) message in the PC-3 cell line was seen when compared with other prostate cell lines. This cell line, which shows an amplification of c-myc (proximal to hccn3 (nov)), induces tumour formation and metastases in nude mice. It is worth noting that the PNT1A cells, which also show an amplification of c-myc, contained small amounts of the hccn3 (nov) transcript, whereas PNT1B cells did not. PNT1A and PNT1B cells did not form colonies in a soft agarose cloning assay. ${ }^{31}$ However, injection of PNT1A cells in ECL (entactin, collagen, laminin) attachment matrix produced tumours in two of five nude mice within 60 days. ${ }^{31}$ hCCN3 (NOV) protein was not detectable by immunocytochemistry in PNT1A cells, possibly because the level of expression was below that which could be detected by this method. Nevertheless, that does not exclude hocn3 (nov) as a component of the tumorigenic properties of PNT1A cells. It is tempting to speculate that hCCN3 (NOV) may have a role in the tumorigenic potential of these cells. Whether this is related to hCCN3 (NOV) expression, c-myc overexpression, or the concomitant expression of both oncogenes remains to be investigated.

The hocn3 (nov) RNA expression pattern was confirmed by immunocytochemistry - all prostate cancer cell lines stained positively for the
hCCN3 (NOV) protein. hCCN3 (NOV) was detected in the cytoplasm of cells, in the perinuclear region, where the protein could be glycosylated or concentrated into secretory vesicles before exocytosis. The heterogeneous staining observed by immunocytochemistry suggests that hCCN3 (NOV) expression could be regulated during the cell cycle. PNT1A and PNT1B cells showed no immunostaining. Because hccn 3 (nov) RNA is overexpressed by an androgen independent cell line (PC-3) it is possible that hocn 3 (nov) expression is related to the hormonal status of the cells. However, serum starvation or stimulation in androgen independent (PC-3) or androgen responsive ( $\mathrm{LNCaP}$ ) cells (serum stimulation or starvation for up to 24 hours) did not show any alteration of hccn 3 (nov) mRNA values (data not shown).

In human tissues, both hyperplastic and neoplastic, hCCN3 (NOV) was found mainly in the acinar epithelial cells, but basal cells, nerves, and endothelial cells also stained. Stromal smooth muscle cells were also focally weakly immunoreactive. Although it is not possible to quantify the immunohistochemical staining, samples from patients 2 and 5 with $\mathrm{BPH}$ showed stronger staining than the other cases, correlating with the hocn3 (nov) RNA expression detected by RT-PCR. It is worth noting that the glandular secretions were also labelled, implying that hCCN3 (NOV) is an exported protein. Prostatic epithelial cells display apocrine secretion, accounting for the positive reaction of the luminal contents. If luminal macrophages ingested such material, it would explain their immunochemical staining.

The function of hCCN3 (NOV) in the prostatic fluid remains unclear. It would be useful to measure hCCN3 (NOV) concentrations in seminal fluid to determine whether it could be used as a marker of biochemical changes that underlie the initiation of hyperplastic changes and perhaps the preneoplastic state.

Few data are available about the expression and role of the CCN proteins in prostate tissue. In the case of Mac25, which is not considered a member of the CCN family, but shares their IGFBP domain, ${ }^{33}$ Hwa et al suggest that its expression is diminished in prostate tumorigenesis, $^{34}$ whereas Degeorges and colleagues ${ }^{35}$ showed that Mac25 is expressed in both in situ and invasive prostate neoplasms, but not typically in normal secretory or BPH epithelium. However, no correlation was found between immunoreacticity for Mac25 and the Gleason grade of the neoplasm. ${ }^{35}$ This pattern of expression of Mac25 is similar to the one we observed for the hCCN3 (NOV) protein. Pilarsky et al have shown that the cancer cell lines DU-145 and PC-3 expressed only small amounts of CCN1 (CYR61), and no CCN1 (CYR61) was detected in the LNCaP cell line. ${ }^{36}$ Moreover, the expression of CCN1 (CYR61) protein is restricted to the epithelium of benign prostate tissue, whereas prostate cancer tissue showed a pronounced decrease of CCN1 (CYR61) protein expression. It has been suggested that $\mathrm{ccn} 1$ (cyr61) expression is inversely related to hccn (nov) expression, implying opposite functions for CCN1 (CYR61) and hCCN3 (NOV). The 
high amounts of hCCN3 (NOV) protein that we detected by immunocytochemistry in the cancer cell lines strengthens this hypothesis. It is intriguing that the CCN1 (CYR61) and HCCN3 (NOV) expression patterns in the prostate cell lines and tissues are the opposite to what is predicted on the basis of their reported expression in growing versus quiescent cells in culture. ${ }^{37}$ However, the coordinate regulation of CCN1 (CYR61) and hCCN3 (NOV) in prostate cells and tissues supports the idea that a CCN1 (CYR61)/hCCN3 (NOV) regulatory axis exists and that it is connected with prostate tumorigenesis.

The role of hCCN3 (NOV) in prostatic neoplasia remains unclear. It could be related to binding of IGF, but hCCN3 (NOV) binds IGF in vitro with a 100-1000 times lower affinity than authentic IGFPB. This does not exclude the possibility that hCCN3 (NOV) binds to other growth factors or proteins that have yet to be identified. Recently, The C-ter domain of hCCN3 (NOV) was found to interact with the extracellular matrix protein fibulin $1 \mathrm{C}$ in a yeast two hybrid assay. This is consistent with a function in protein-protein interaction for this domain and for the hCCN3 (NOV) protein. ${ }^{26}$

We conclude that the differential expression of hccn3 (nov) RNA and protein in prostate cell lines and tissues may mean that this protooncogene is involved in prostate tumorigenesis. We suggest that hCCN3 (NOV) may act as a modulator of stromal-epithelial interactions mediated by peptide growth, enhancing or lessening their effects on cell growth and function. Our results emphasise the importance of investigating the expression and regulation of the CCN proteins in prostate disease. Further analysis of hccn3 (nov) expression in normal prostate specimens and samples at different stages of disease will help to establish a putative association between prostate cancer and hccn3 (nov) expression and further our understanding of prostate tumour development and progression.

This work was supported in part by the Norfolk and Norwich Health Care NHS Trust, a grant from Mrs M Doggett, and the Norfolk and Norwich Big C Appeal Partners in Cancer Research initiative. BT acknowledges the support of Ligue National Centre le Cancer (Comitês du Cher et de l'Indre). RT would like to thank Dr A Padilla and Dr I Gibson for fruitful discussions and Dr A Degeorges for valuable comments during the preparation of this manuscript.

1 Kallioniemi OP, Visakorpi T. Genetic basis and clonal evolution of human prostate cancer. Adv Cancer Res 1996;68:225-55.

2 Bostwick DG, Pacelli A, Lopez-Beltran A. Molecular biology of prostatic intraepithelial neoplasia. Prostate 1996; 29:117-34.

3 Qian J, Bostwick DG, Takahashi S, et al. Chromosomal anomalies in prostatic intraepithelial neoplasia and carcinoma detected by fluorescence in situ hydridization. Cancer Res 1995;55:5408-14.

4 Takahashi S, Alcaraz A, Brown JA, et al. Aneusomies of chromosomes 8 and $\mathrm{Y}$ detected by fluorecence hybridization are prognostic markers for pathological stage C (pT3N0M0) prostate carcinoma. Clin Cancer Res 1996;2:137-45.

5 Buttyan R, Sawczuk IS, Benson MC, et al. Enhanced expression of the c-myc proto-oncogene in high-grade human prostate cancers. Prostate 1987;11:327-37.

6 Fleming WH, Hamel A, MacDonald R, et al. Expression of the c-myc protoncogene in human prostatic carcinoma and benign prostatic hyperplasia. Cancer Res 1986;46:1535-8.

7 Jenkins RB, Qian J, Lieber MM, et al. Detection of c-myc oncogene amplification and chromosomal anomalies in metastatic prostatic carcinoma by fluorescence in situ metastatic prostatic carcinoma by fluor
hybridization. Cancer Res 1997;57:524-31.

8 Matusik RJ, Fleming WH, Hamel A, et al. Expression of the c-myc proto-oncogene in prostatic tissue. Prog Clin Biol Res 1987;239:91-112.
9 Degeorges A, Hoffschir F, Cussenot O, et al. Recurrent cytogenetic alterations of prostate carcinoma and amplification of c-myc or epidermal growth factor receptor in subclones of immortalized PNT1 human prostate epithelial cell line. Int 7 Cancer 1995;62:724-31.

$10 \mathrm{Nag}$ A, Smith RG. Amplification, rearrangement, and elevated expression of c-myc in the human prostatic carcinoma cell line LNCaP. Prostate 1989;15:115-22.

11 Martinerie C, Viegas-Pequignot E, Guenard I, et al. Physical mapping of human loci homologous to the chicken nov proto-oncogene. Oncogene 1992;7:2529-34.

12 Joliot V, Martinerie C, Dambrine G, et al. Proviral rearrangements and overexpression of a new cellular gene (nov) in myeloblastosis-associated virus type 1-induced nephrobastomas. Mol Cell Biol 1992;12:10-21.

13 Perbal B. Contribution of mav-1-induced nephroblastoma to the study of genes involved in human Wilms-tumor development. Crit Rev Oncog 1995;5:589-613.

14 Chevalier G, Yeger H, Martinerie C, et al. novH: differential expression in developing kidney and Wilms' tumors. Am $\mathcal{F}$ Pathol 1998;152:1563-75.

15 Bork P. The modular architecture of a new family of growth regulators related to connective tissue growth factor. FEBS Lett 1993;327:125-30.

16 Collet C, Candy J. How many insulin-like growth factor binding proteins? Mol Cell Endocrinol 1998;139:1-6.

17 Bradham DM, Igarashi A, Potter RL, et al. Connectivetissue growth-factor - a cysteine-rich mitogen secreted by human vascular endothelial cells is related to the Srcinduced immediate early gene product CEF-10. F Cell Biol 1991;114:1285-94.

18 O'Brien TP, Yang GP, Sanders L, et al. Expression of Cyr61, a growth factor-inducible immediate-early gene. Mol Cell Biol 1990;10:3569-77.

19 Hashimoto Y, Shindo-Okada N, Tani M, et al. Expression of the Elm1 gene, a novel gene of the CCN (connective tissue growth factor, Cyr61/CEF10, and neuroblastoma overexpressed gene) family, suppresses in vivo tumor growth and metastasis of K-1735 murine melanoma cells. F Exp Med 1998; 187:289-96.

20 Grotendorst GR, Lau LF, Perbal B. CCN proteins are distinct from and should not be considered members of the insulin-like growth factor-binding protein superfamily. Endocrinology 2000;141:2254-6.

21 Kireeva ML, Latinkic BV, Kolesnikova TV, et al. Cyr61 and Fisp12 are both ECM-associated signaling molecules: activities, metabolism, and localization during development. Exp Cell Res 1997:233:63-77.

22 Kolesnikova TV, Lau FF. Human CYR61-mediated enhancement of bFGF-induced DNA synthesis in human umbilical vein endothelial cells. Oncogene 1998;16:747-54.

23 Yang GP, Lau LF. Cyr61, product of a growth factorinducible immediate early gene, is associated with the extracellular matrix and cell surface. Cell Growth Differ $1991 ; 2: 351-7$

24 Grotendorst G, Okochi H, Hayashi N. A novel transforming growth factor $\beta$ response element controls the expression of the connective tissues growth factor gene. Cell Growth Differ 1996;2:225-33.

25 Perbal B. Characterization and expression of the human nov protooncogene in Wilms-tumors. Bull Cancer 1994;81: 957-61.

26 Perbal B, Martinerie C, Sainson R, et al. The C-terminal domain of the regulatory protein $\mathrm{NOVH}$ is sufficient to promote interaction with fibulin 1C: a clue for a role of NOVH in cell-adhesion signaling. Proc Natl Acad Sci US A 1999;96:869-74

27 Perbal B. Nuclear localisation of NOVH protein: a potential role for NOV in the regulation of gene expression. 7 Clin Pathol: Mol Pathol 1999;52:84-91.

28 Martinerie C, Huff V, Joubert I, et al. Structural analysis of the human nov proto-oncogene and expression in Wilm's tumors. Oncogene 1994;9:2729-32.

29 Martinerie C, Chevalier G, Rauscher FJ, et al. Regulation of nov by WT1: a potential role for nov in nephrogenesis. Oncogene 1996;12:1479-92.

30 Scholz G, Martinerie C, Perbal B, et al. Transcriptional down regulation of the nov proto-oncogene in fibroblasts transformed by p60 ${ }^{\text {v-src }}$. Mol Cell Biol 1996;16:481-6.

31 Cussenot O, Berthon P, Berger R, et al. Immortalization of human adult normal prostatic epithelial cells by liposomes containing large T-SV40 gene. F Urol 1991;143:881-6.

32 Burren CP, Wilson EM, Hwa V, et al. Binding properties and distribution of insulin-like growth factor binding protein-related protein 3 (IGFBP-rP3/NovH), an additional member of the IGFBP superfamily. $f$ Clin Endocrinol Metab 1999;84:1096-103.

33 Oh Y, Nagalla SR, Yamanaka Y, et al. Synthesis and characterization of insulin-like growth factor-binding protein (IGFBP)-7. F Biol Chem 1996;271:30322-5.

34 Hwa V, Tomasini Spenger T, Bermejo AL, et al. Characterization of insulin-like growth factor-binding protein-related protein-1 in prostate cells. I Clin Endocrinol Metab 1998;83:4355-62.

35 Degeorges A, Wang F, Frierson HF, et al. Human prostate cancer expresses the low affinity insulin-like growth factor binding protein IGFBP-rP1. Cancer Res 1999;59:2787-90.

36 Pilarsky CP, Schmidt U, Essrich C, et al. Expression of the extracellular matrix signalling molecule Cyr61 is downregulated in prostate cancer. Prostate 1998;36:85-91.

37 Lau LF, Lam SC-T. The CCN family of angiogenic regulators: the integrin connection. Exp Cell Res 1999;248: 